\title{
A likely increase in fine particulate matter and premature mortality under future climate change
}

\author{
S. Park ${ }^{1}$ (D) $\cdot$ R. J. Allen ${ }^{2}$. C. H. Lim ${ }^{3}$
}

Received: 31 October 2018 / Accepted: 27 December 2019 / Published online: 4 January 2020

(C) The Author(s) 2020

\begin{abstract}
Climate change modulates the concentration of fine particulate matter $\left(\mathrm{PM}_{2.5}\right)$ via modifying atmospheric circulation, temperature, and the hydrological cycle. Furthermore, $\mathrm{PM}_{2.5}$ is associated with cardiopulmonary diseases and premature mortality. Here, we use seven models to assess the response of $\mathrm{PM}_{2.5}$ to end of the twenty-first century climate change under Representative Concentration Pathway 8.5, and the corresponding impact on premature mortality. The majority of models yield an increase in both $\mathrm{PM}_{2.5}$ and premature mortality associated with lung cancer and cardiopulmonary disease in all world regions except Africa. These results are robust across five different future population projections, although the magnitude of premature deaths can vary by up to a factor of two. Much larger uncertainty is related to uncertainty in model physics and the representation of aerosol processes. Although our analysis requires several assumptions related to future population estimates, as well as the concentrationresponse function, results suggest that future emission reductions are necessary to avoid the likely health risks associated with increasing $\mathrm{PM}_{2.5}$ in a warmer world.
\end{abstract}

Keywords Climate change $\cdot$ GHG-induced warming $\cdot$ Fine particulate matter $\cdot$ Premature mortality

\section{Introduction}

Air pollutant concentrations vary depending on diverse factors including emissions, weather, and climate change (Jacob and Winner 2009; Mickley et al. 2004; Westervelt et al. 2016). It is important to understand how aerosol burden changes in the future under diverse emission scenarios to improve air pollution policy decision-making. Recent studies suggest that future climate change related to continued greenhouse gas

Electronic supplementary material The online version of this article (https://doi.org/10.1007/s11869-019-00785-7) contains supplementary material, which is available to authorized users.

S. Park

spark092@snu.ac.kr

R. J. Allen

robert.allen@ucr.edu

1 School of Earth and Environmental Sciences, Seoul National University, Seoul 08826, Republic of Korea

2 Department of Earth and Planetary Sciences, University of California, Riverside, Riverside, CA 92521, USA

3 Department of Environmental Science and Ecological Engineering, Korea University, Seoul 02841, Republic of Korea
(GHGs) emissions has significant effects on aerosol burden and air pollutant concentration, independent of any change in emissions (Allen et al. 2016; Shen et al. 2016; Westervelt et al. 2016).

Westervelt et al. (2016) finds that climate change yields an increase in $\mathrm{PM}_{2.5}$ in all but one of the Representative Concentration Pathways (RCPs), and relates this to local temperature increases. Similarly, Allen et al. (2016) shows that GHG-induced warming yields increases in surface concentration and burden of both anthropogenic and natural aerosols, and this is related to enhanced land-warming and continental aridity (Allen et al. 2019). Anthropogenic aerosols, including black carbon (BC), primary organic matter (POM), and sulfate $\left(\mathrm{SO}_{4}\right)$, generally increase more than natural aerosols, such as dust and sea salt. In addition, the increase in anthropogenic aerosols primarily occurs over the Northern Hemisphere midlatitude continents during summertime, which they relate to a corresponding decrease in aerosol wet removal driven by a reduction in large-scale precipitation.

An increase in air pollutant concentration, especially fine particulate matter $\left(\mathrm{PM}_{2.5}\right)$, is associated with an increase in premature mortality (Lelieveld et al. 2015; Nawahda et al. 2012; Silva et al. 2013). Hence, previous studies have focused on how future climate change affects $\mathrm{PM}_{2.5}$ concentrations, and the corresponding impacts on mortality (Fang et al. 2013; 
Silva et al. 2017). Fang et al. (2013) examines the effects of climate change due to GHGs on $\mathrm{PM}_{2.5}$ air quality over the twenty-first century using a global coupled chemistryclimate model. The results show that global annual premature mortality increases by almost 100,000 deaths. Silva et al. (2017) estimates premature mortality related to four diseases under future climate change using an ensemble of global chemistry climate models. Their multi-model average results indicate an increase in global premature mortality in both 2030 and 2100 at $55,600(-34,300$ to 164,000$)$ and 215,000 $(-76,100$ to 595,000$)$ deaths/year, respectively. In addition, all world regions yield an increase in premature deaths, except Africa.

Here we assess changes in $\mathrm{PM}_{2.5}$ concentration due to climate change derived from a business-as-usual scenario (RCP8.5), with large twenty-first century warming (e.g., Moss et al. 2010), using five state-of-the-art chemistryclimate models that participated in the Atmospheric Chemistry and Climate Model Inter-comparison Project (ACCMIP) and in-house Community Atmosphere Model versions 4 and 5 (CAM4/5) simulations. In addition, premature mortality related to lung cancer (LC) and cardiopulmonary disease (CPD) is estimated using $\mathrm{PM}_{2.5}$ changes and five different future population projections for the end of the twentyfirst century.

To quantify robust changes (i.e., consistent changes over multiple models), our study uses several different global chemistry-climate models. Post et al. (2012) and Silva et al. (2013) suggest that using a single model may yield significant uncertainty; therefore, multiple models are required to determine how robust the effects of climate change are on $\mathrm{PM}_{2.5}$ concentration. Therefore, in this study, we emphasize model agreement, and focus on changes in which the majority of models agree (i.e., at least four of the seven models). Although our analysis is similar to Silva et al. (2017), including the evaluation of ACCMIP models, three major distinctions include the following: (1) we focus on archived $\mathrm{PM}_{2.5}$ from all ACCMIP models, except HadGEM2 (which lacks archived $\mathrm{PM}_{2.5}$ ); (2) we use five different estimates of future population to quantify uncertainty in premature deaths due to uncertainty in future population projections; and (3) we conduct our own in-house CAM4/5 simulations using an experimental design analogous to that used in ACCMIP, and evaluate the corresponding changes in $\mathrm{PM}_{2.5}$ and premature deaths.

\section{Methods}

We use $\mathrm{PM}_{2.5}$ mass mixing ratio from the Atmospheric Chemistry and Climate Model Intercomparison Project (ACCMIP) (Lamarque et al. 2013) and CAM4/5 simulations to evaluate changes in $\mathrm{PM}_{25}$ concentration due to GHGinduced climate change at the end of the twenty-first century.
Two time-slice experiments, representing climate in the year 2000 and 2100, are used. In most cases, 10 years is available for both the preset-day and the future simulation (Table S1). Both experiments feature identical anthropogenic aerosol emissions from the year 2000; the end of the twenty-first century simulation uses sea surface temperatures, sea-ice concentrations, and GHGs based on RCP8.5, a business-as-usual scenario with maximum warming. RCP8.5 is the only future scenario ACCMIP models used to perform these experiments. These simulations also use prescribed biomass burning emissions and account for climate-induced changes in natural aerosol emissions (dust and sea salt) (Lamarque et al. 2010, 2013). Biogenic emissions vary depending on the model (see Lamarque et al. 2013). CAM4/5 simulations are conducted using an analogous experimental design as ACCMIP, with sea surface temperature and sea-ice concentration anomalies from the ensemble mean of 18 Coupled Model Intercomparison Project version 5 (CMIP5) RCP8.5 models (2090-2099 relative to 2006-2015) and RCP8.5 GHGs based on the 2090-2099 mean.

We calculate annual mean $\mathrm{PM}_{2.5}$ values using monthly average data from each model. Comparison of the two experiments (2100 minus 2000) yields the change in $\mathrm{PM}_{2.5}$ concentration at the end of the twenty-first century under GHGinduced climate change. We use each model's lowest vertical level to represent surface concentration.

Five ACCMIP models (Table S1) archived the necessary data, including archived $\mathrm{PM}_{2.5}$ mass mixing ratios, or individual aerosol species' mass mixing ratios that can be used to approximate $\mathrm{PM}_{2.5}$. Since the Hadley Centre Global Environmental Model version 2 (HadGEM2) (Collins et al. 2011) lacks archived $\mathrm{PM}_{2.5}$, we estimate it using Eq. [1] (Silva et al. 2013) and six reported aerosol species: black carbon $(\mathrm{BC})$, organic aerosol $(\mathrm{OA})$, sulfate $\left(\mathrm{SO}_{4}\right)$, secondary organic aerosol (SOA), sea salt (SS), and dust. CAM4/5 $\mathrm{PM}_{2.5}$ mass mixing ratio is obtained by summing all non-coarse mode aerosol species. For CAM5, this includes the non-coarse mode components of the six aerosol species above; for CAM4, five of the six species are used, as CAM4 lacks SOA. Note that these models, in general, are not chemistry-climate models, and therefore contain a simplified representation of aerosols.

Estimated $\mathrm{PM}_{2.5}=\mathrm{BC}+\mathrm{OA}+\mathrm{SO}_{4}+\mathrm{SOA}+0.25 * \mathrm{SS}$

$$
+0.1 * \text { Dust }
$$

Thus, in most models, $\mathrm{PM}_{2.5}$ is based on six species. However, in CAM4, no SOA is included, so $\mathrm{PM}_{2.5}$ is based on five species. In GFDL-AM3 and GISS-E2-R, ammonium sulfate $\left(\mathrm{NH}_{4}\right)$ and nitrate $\left(\mathrm{NO}_{3}\right)$ are also included, so $\mathrm{PM}_{2.5}$ is based on eight species. This implies differences in the composition of $\mathrm{PM}_{2.5}$ across some models. We prefer to focus on actual $\mathrm{PM}_{2.5}$, as opposed to the alternative approach whereby $\mathrm{PM}_{2.5}$ is approximated by Eq. [1] for all models (e.g., Silva 
et al. 2017). Although the use of Eq. [1] supplies $\mathrm{PM}_{2.5}$ with uniform composition across all models, it is an approximation to the actual $\mathrm{PM}_{2.5}$, and as such, differences can arise. We find, for example, that this approximation can affect the $\mathrm{PM}_{2.5}$ response, and the corresponding model agreement ("Changes in surface PM2.5 concentration").

We estimate premature mortality associated with changes in $\mathrm{PM}_{2.5}$ concentration due to climate change using health impact functions Eq. [2] (Anenberg et al. 2010; Silva et al. 2013).

$\Delta$ Mort $=$ Mort $_{\text {base }}\left(1-\mathrm{e}^{-\beta \Delta \chi}\right)$ Pop

where Mort $_{\text {base }}$ is the baseline mortality rate, $\beta$ is concentration-response factor (CRF), $\Delta \mathrm{x}$ is the change in $\mathrm{PM}_{2.5}$ concentration between the present and future climate, and Pop is the exposed population age 30 and above in the year 2100 (Fig. S1). Baseline mortality rate and $\beta$ values are obtained from Silva et al. (2013), the latter of which is based on the American Cancer Society (ACS; Krewski et al. 2009). $\beta$ is estimated from the slope of the log linear relation between $\mathrm{PM}_{2.5}$ concentration and relative risk (RR) (i.e., $\mathrm{RR}=\mathrm{e}^{\beta \Delta x}$ ) (Anenberg et al. 2010; Krewski et al. 2009; Silva et al. 2013).

A recent study (Burnett et al. 2014) developed another health impact assessment method, calculating RR using the integrated exposure-response (IER) relationship. The IER function compiles cohort studies of ambient air pollution and tobacco smoke activities to better quantify exposureresponse relation, particularly at higher $\mathrm{PM}_{2.5}$ concentrations $\left(\sim>100 \mu \mathrm{g} / \mathrm{m}^{3}\right.$, where the curve flattens out). Thus, it may better estimate RR in extremely polluted regions, including China and India. In this study, however, the American Cancer Society's CRF is used because this cohort includes the largest population of the available long-term $\mathrm{PM}_{2.5}$ studies (Hoek et al. 2002; Lepeule et al. 2012). Studies on the effects of $\mathrm{PM}_{2.5}$ on premature mortality are generally consistent across different countries (Hoek et al. 2002; Health Effects Institute 2004; 2010), and CRFs are not a strong function of sex, age, or race (Krewski et al. 2009; Jerrett et al. 2009). Thus, we apply our CRF globally. In addition, our study involves changes in $\mathrm{PM}_{2.5}$ concentration that are relatively low $\left(<100 \mu \mathrm{g} / \mathrm{m}^{3}\right)$ over most of the world. We note that differences in the composition of pollution, susceptibility, and underlying health may lead to differences in the response to $\mathrm{PM}_{2.5}$. Furthermore, the CRF used in this study is based on the present day and this does not account for possible changes in the CRF (e.g., changes in susceptibility). These factors contribute to additional uncertainty in our future premature mortality projections.

To calculate premature mortality associated with future changes in $\mathrm{PM}_{2.5}$, an estimate of future (year 2100) population age 30 and above is required. Three datasets are used to estimate this quantity: present-day (2014) population for all ages from LandScan (Bhaduri et al. 2002); country-level presentday total population age 30 and over from United Nation's (UN) Department of Economic and Social Affairs (United Nation, data available at https://esa.un.org/unpd/wpp/ Download/Standard/Population/); and country-level projected (year 2100) total population age 30 and over from the Shared Socioeconomic Pathways (SSPs) scenario database. LandScan present-day population for all ages is provided at $<1 \mathrm{~km}^{2}$ spatial resolution. However, the UN and SSP population datasets provide country-level estimates. Therefore, we unify all population datasets to a spatial resolution of $0.5^{\circ}$ by $0.5^{\circ}$ using ArcGIS 10.3 resample tool.

The SSPs characterize five possible future development pathways derived from different assumptions on society's capability to mitigate and/or adapt to climate change (O'Neill et al. 2014; Riahi et al. 2017; Samir and Wolfgang 2017). These include sustainability (SSP1), middle of the road (SSP2), fragmentation (SSP3), inequality (SSP4), and conventional development (SSP5). The SSP5 scenario represents the development of fossil fuels, which is similar to RCP8.5. The SSP populations are projected with alternative fertility, mortality, migration, and education levels, which is dependent on the country (Samir and Wolfgang 2017).

Our approach has two assumptions: (1) the ratio of population age 30 and above to total population is uniformly distributed within each country, and (2) the spatial distribution of future population is identical to the present-day spatial distribution within each country. We note that these assumptions are over simplifications, and contribute additional uncertainty to our analysis. For example, world population forecasts indicate an increase in the percentage of urban population (i.e., the spatial distribution of future population in urban areas will be larger than in present-day).

We first calculate the country-level ratio of population 30 and above in the present-day, by dividing population age 30 and above by the total population within each country. This ratio is multiplied by the present-day all ages population in each grid box for each country (first assumption), yielding the present-day population age 30 and above in each grid box using ArcGIS 10.3 raster calculator tools. We obtain the ratio of population age 30 and above in the present-day for each grid box by dividing population age 30 and above in each grid box by the total population age 30 and above within each country. Finally, we multiply the ratio to the projected future population age 30 and above to quantify the future population age 30 and above in each grid box (second assumption). We show the estimated future spatial distribution of population age 30 and above based on SSP5 (Fig. S1). Note that the increase in population implies more people will be exposed to $\mathrm{PM}_{2.5}$.

Across scenarios, we find projected population age 30 and above ranges from $\sim 6.1$ to 7.9 billion in SSP1 and SSP3, respectively (Table S2). Moreover, among ten world regions, 
the largest (smallest) increase in future population age 30 and above, averaged over the five scenarios, occurs in India (Australia) at 1.76 (0.03 billion) (Table S2). Notable population increases exist in all SSPs in several regions, including western/central Africa and India. In contrast, Eastern Europe and China show decreases in future population age 30 and above. Furthermore, the largest population increase occurs over India, particularly based on SSP3 (Fig. S2).

\section{Results}

\section{Changes in surface $\mathrm{PM}_{2.5}$ concentration}

Figure 1 shows regions where the majority (at least 4 out of 7 ) agree on an increase or decrease in continental annual mean $\mathrm{PM}_{2.5}$ concentration at the end of the twenty-first century under RCP8.5. Most land areas show at least four models agree on an increase in $\mathrm{PM}_{2.5}$. Moreover, at least five models agree on elevated $\mathrm{PM}_{2.5}$ over many locations, such as northern India, Western Europe, Australia, and the eastern/western United States. Only a few regions show model agreement on a decrease in $\mathrm{PM}_{2.5}$ concentration, including central Africa, Greenland, and Northwestern China.

Similar to the regional agreement, the majority of models also yield an increase in global annual mean $\mathrm{PM}_{2.5}$ attributable to GHG-induced warming (Table S3). In fact, six of the seven models yield an increase in global mean $\mathrm{PM}_{2.5}$, with a model mean increase of $0.43 \mu \mathrm{g} / \mathrm{m}^{3}$ and a range from $-0.25 \mu \mathrm{g} / \mathrm{m}^{3}$ (CAM4) to $1.71 \mu \mathrm{g} / \mathrm{m}^{3}$ (MIROC-CHEM). Moreover, five of the seven models indicate an increase in $\mathrm{PM}_{2.5}$ in nine of the ten world regions (Africa being the exception). The largest increase in $\mathrm{PM}_{2.5}$, averaged over the seven models, occurs over India at $1.5 \mu \mathrm{g} / \mathrm{m}^{3}$, with six of the seven models agreeing on the increase. Similarly, the largest decrease in $\mathrm{PM}_{2.5}$ occurs over Africa at $0.9 \mu \mathrm{g} / \mathrm{m}^{3}$, with five of the seven models agreeing on the decrease. These results suggest that business-as-usual GHGinduced warming is likely associated with an increase in surface $\mathrm{PM}_{2.5}$ concentration over most land regions. Similar results are obtained by Silva et al. (2017), including a global mean model mean $\mathrm{PM}_{2.5}$ increase of $0.54 \mu \mathrm{g} / \mathrm{m}^{3}$ and a range from $-0.4 \mu \mathrm{g} /$ $\mathrm{m}^{3}$ to $1.5 \mu \mathrm{g} / \mathrm{m}^{3}$. Note that Silva et al.'s (2017) changes are weighted by exposed population (adults aged 25 and older), as they did not include raw $\mathrm{PM}_{2.5}$ responses.

A relatively large increase in $\mathrm{PM}_{2.5}$ (more than $3 \mu \mathrm{g} / \mathrm{m}^{3}$ ) occurs over several areas (Fig. S3), including western Australia, northern Africa, North America, India, and East China. Most of the decrease in $\mathrm{PM}_{2.5}$ concentration occurs over the oceans and parts of Africa-particularly in five models including GISS-E2-R, NCAR-CAM3.5, HadGEM2, CAM4, and CAM5.

Although our $\mathrm{PM}_{2.5}$ results are similar to Silva et al. (2017), subtle differences do exist, including a slight reduction in model agreement based on our analysis, relative to Silva et al. (2017). Part of this difference is due to our use of two additional models (CAM4/5). CAM5, for example, yields decreases in $\mathrm{PM}_{2.5}$ over several regions, including North America, Africa, East Asia, Southeast Asia, and Australia (Table S3). Another source of the difference between these two analyses appears to be related to the definition of $\mathrm{PM}_{2.5}$. As previously noted, we use actual (i.e., archived) $\mathrm{PM}_{2.5}$ in all but one model. The exception is HadGEM2 (which lacks archived $\mathrm{PM}_{2.5}$ ), where Eq. [1] is used to approximate $\mathrm{PM}_{2.5}$. Silva et al. (2017) use Eq. [1], with the addition of ammonium sulfate, for all five ACCMIP models. We reproduce $\mathrm{PM}_{2.5}$ model agreement — using only the ACCMIP models that Silva et al. (2017) use - based on approximating $\mathrm{PM}_{2.5}$ as the sum of six species [Eq. 1] (ammonium sulfate is not included, despite its inclusion in Silva et al. (2017), since this data is not publically available for all models). When approximated as the sum of six species, we find that more ACCMIP models agree on an increase in $\mathrm{PM}_{2.5}$ over several regions, including North America, western and central Africa, and Europe
Fig. 1 Model agreement on increased (red color) or decreased (blue color) continental annual mean PM2.5 concentration at the end of the twenty-first century under RCP8.5. Colors show where the majority of models agree (i.e., at least 4 out of 7)

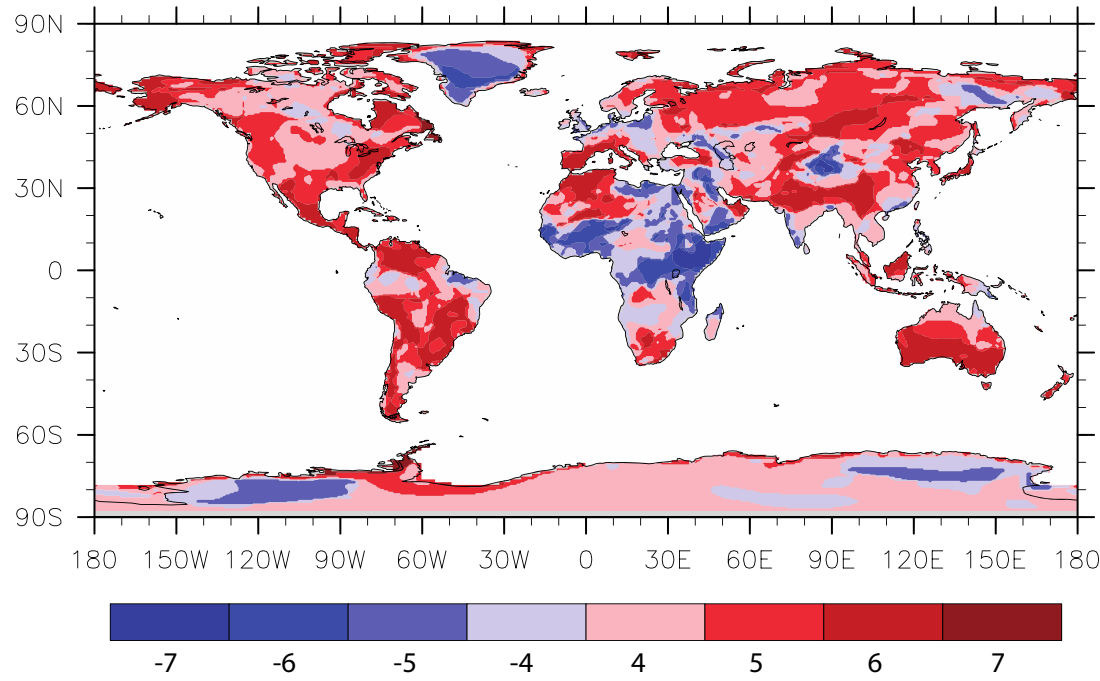


(Fig. S4). We note that Silva et al. (2017) also attempts to quantify the effect of approximating $\mathrm{PM}_{2.5}$ as the sum of species relative to actual $\mathrm{PM}_{2.5}$, and they too find some differences.

A more like for like comparison is obtained by approximating $\mathrm{PM}_{2.5}$ with Eq. [1] using the exact same aerosol species that constitute archived $\mathrm{PM}_{2.5}$ (i.e., 8 species for GFDL-AM3 and GISS-E2-R and 6 species for the other models, except CAM4 which is based on 5 species). When $\mathrm{PM}_{2.5}$ is approximated as the sum of individual aerosol species, most regions yield discrepancies in the $\mathrm{PM}_{2.5}$ response, relative to actual $\mathrm{PM}_{2.5}$ (Fig. S5). Despite these differences, however, our results are very similar to Silva et al. (2017) - the majority of models yield a $\mathrm{PM}_{2.5}$ increase in all world regions except Africa.

\section{Effects of $\mathrm{PM}_{2.5}$ changes on premature mortality}

Estimated premature mortality due to lung cancer (LC) and cardiopulmonary disease (CPD) associated with the change in $\mathrm{PM}_{2.5}$ indicates a robust increase. Figure 2 shows elevated premature mortality in the majority of models (four of the seven) within nine of the ten world regions (Table S4). Moreover, stronger inter-model agreement (at least five models) occurs over eight of the ten regions (Africa and Australia are the exceptions). These results are consistent with the strong inter-model agreement that surface $\mathrm{PM}_{2.5}$ concentrations will increase in these regions (Fig. 1; Table S3). On the contrary, all models indicate a decrease in premature deaths over Africa across all future population scenarios (Table S4). Figure 3 shows the spatial distribution of premature mortality for each of the seven models. The majority of models yield a decrease in premature deaths over central and western Africa, and increases in premature deaths over the eastern United States, southwestern Europe, northern India, Australia, and east China.

Averaged over the seven models, the global average premature mortality increases in all future-population scenarios, with a model mean increase of 194,448 deaths/year. However, the magnitude varies depending on the SSP, ranging by a factor of 2: from 143,704 deaths/year in SSP4 to 265,112 deaths/year in SSP3 (Fig. 4). This range of future premature mortality due to GHG-induced changes in $\mathrm{PM}_{2.5}$ covers the corresponding estimate of 215,000 deaths/year (based on four diseases) using future-population projections from the International Futures (IFs) integrated modeling system (Silva et al. 2017). We note that model uncertainty, relative to future population uncertainty, is the dominant source of ambiguity in premature deaths. Compared with the factor of $\sim 2$ uncertainty due to SSP (143,704 versus 265,112 global deaths/year), the uncertainty due to the model ranges from - 249,976 deaths/year in HadGEM2 to 1,043,850 million deaths/year in MIROC-CHEM (averaged over SSP for each model). This is qualitatively similar to Silva et al. [2017], although they find a smaller range in model uncertainty for global premature deaths (based on four diseases and IF future population) at $-76,100$ to 595,000 .

Similar conclusions exist for regional annual mean premature mortality, which spans a large range across the SSPs and, in particular, the models (Fig. S6; Table S5). In many regions, including Africa, India, East Asia, and the Middle East, the magnitude of premature mortality is heavily modulated by the model, as opposed to the SSP. For example, except for HadGEM2, models show a large increase in premature deaths over India with SSP3, with a range from 60,176 (CAM5) to 931,800 (MIROCCHEM) deaths/year. HadGEM2 yields a decrease of $-172,866$ deaths/year. In contrast, the range of premature deaths due to SSP, for a given region and model, is generally much smaller, but can still be factor of $\sim 2$. In MIROC-CHEM, for example, premature mortality over India ranges from 571,016 in SSP4 to 931,800 in SSP3. These results imply that much of the uncertainty in future premature deaths due to GHG-induced climate change is due to uncertainty in model physics and the representation of aerosol processes. However, although future population is a smaller component of the uncertainty, it still contributes a factor of $\sim 2$ to the uncertainty in future premature deaths.
Fig. 2 Number of models that yield an increase in premature mortality at the end of the twentyfirst century (SSP5 scenario)

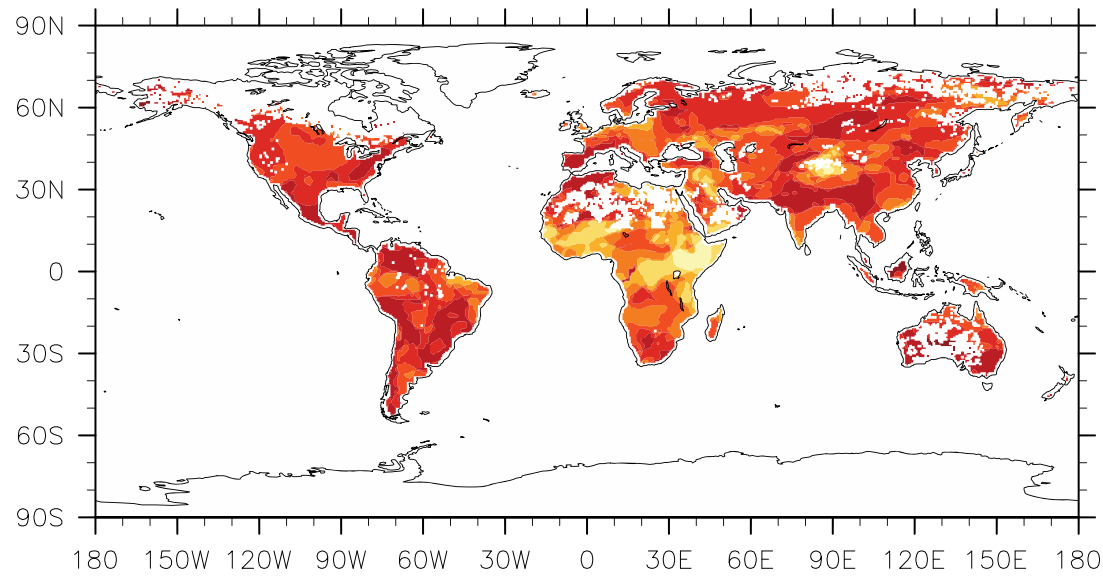

\begin{tabular}{|l|l|l|l|l|l|l|l|}
\hline & & & & & & & \\
\hline 0 & 1 & 2 & 3 & 4 & 5 & 6 & 7 \\
\hline
\end{tabular}



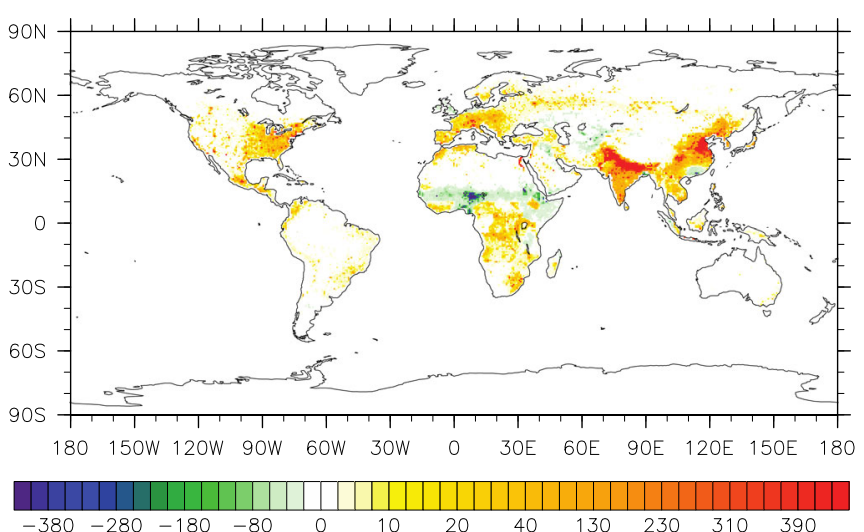

(a)
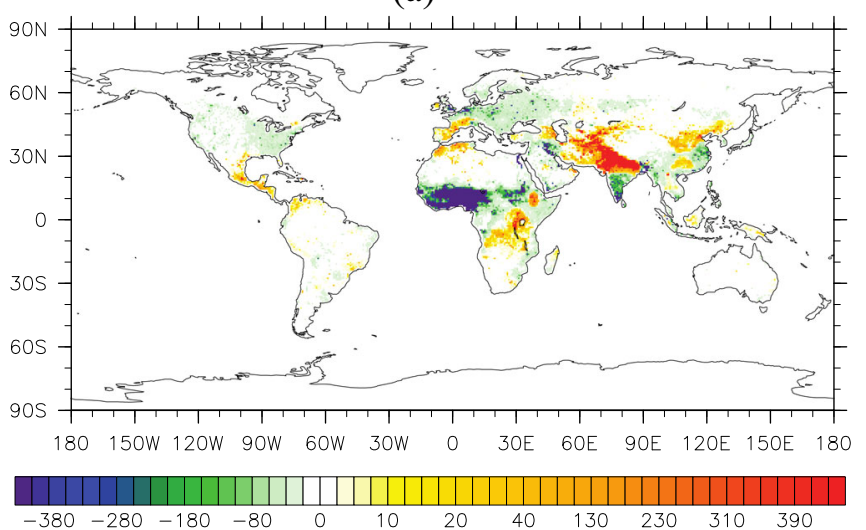

(c)
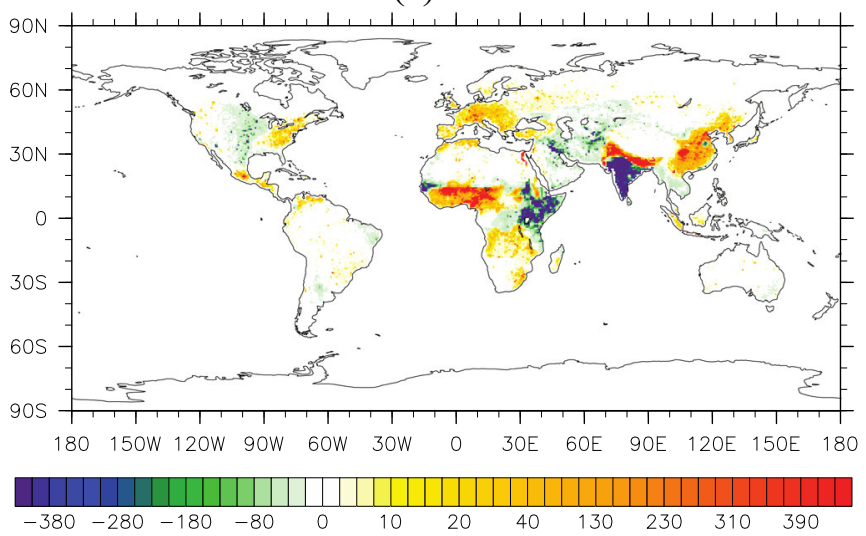

(e)
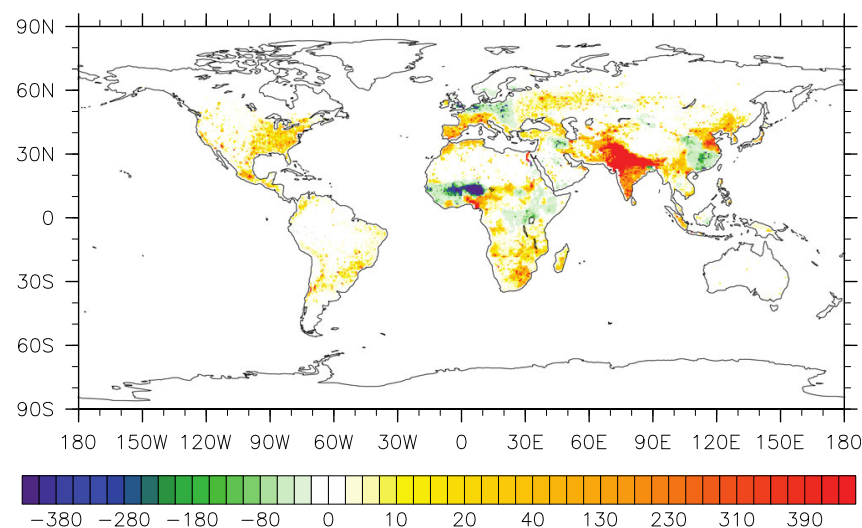

(b)
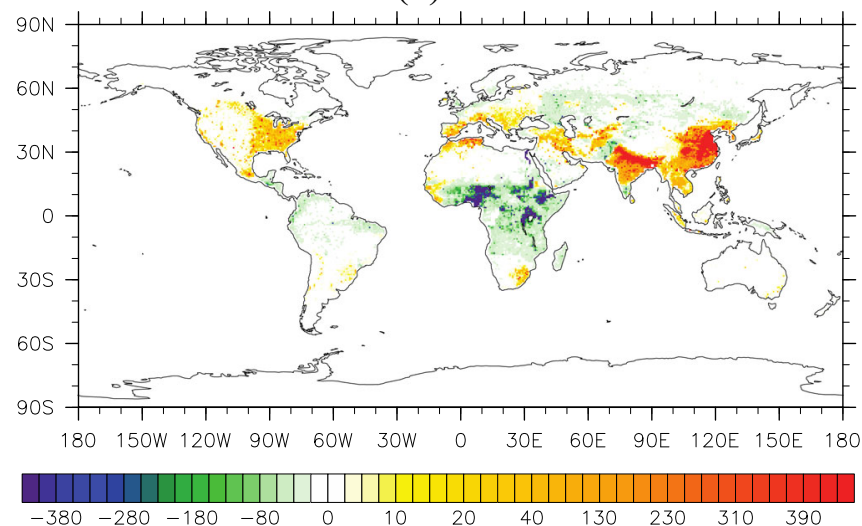

(d)
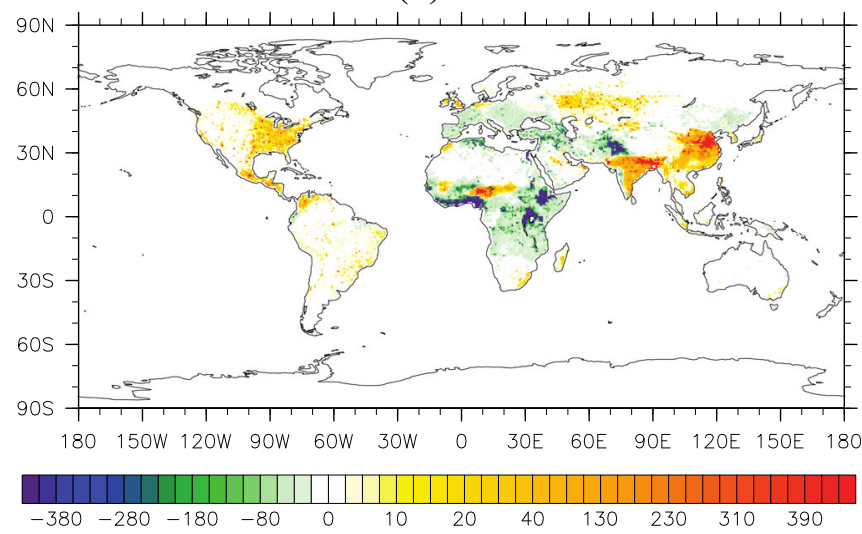

(f)

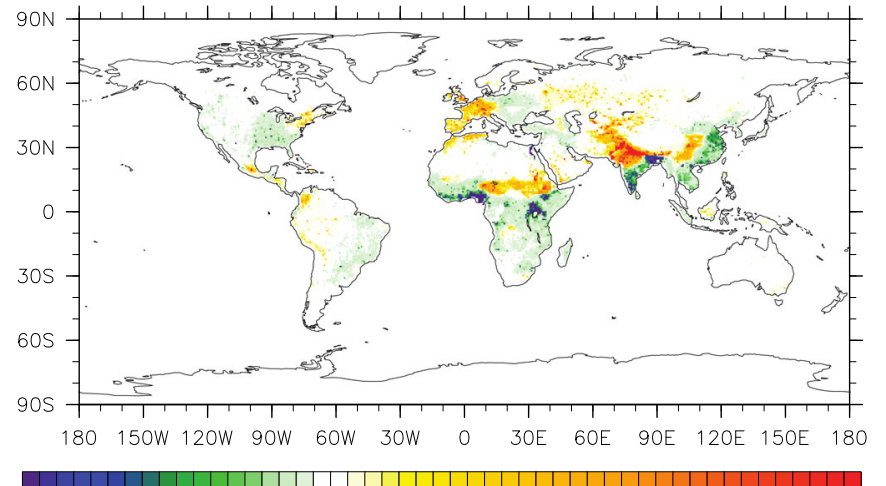

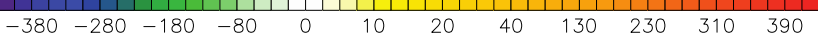

(g) 
Fig. 3 Annual premature mortality (SSP5 scenario) due to both LC and CPD in the year 2100 due to changes in PM2.5 concentration from a GFDL-AM3, b MIROC-CHEM, c GISS-E2-R, d NCAR-CAM3.5, e HadGEM2, f CAM4, and g CAM5 (units: deaths $/ 10,000 \mathrm{~km}^{2}$ ). The other SSPs yield a similar spatial mortality distribution, but with different magnitudes (Table S4-S5). White land areas indicate no exposed population

\section{Conclusion and discussion}

We assess how business-as-usual GHG-induced climate change influences $\mathrm{PM}_{2.5}$ concentration at the end of the twenty-first century using seven models, including five ACCMIP models and inhouse simulations with CAM4/5. Both lung cancer (LC) and cardiopulmonary disease (CPD) premature mortality due to future $\mathrm{PM}_{2.5}$ concentration changes are also evaluated. The results indicate that climate change has a significant impact on surface $\mathrm{PM}_{2.5}$ concentration. Globally, six of seven models yield an increase in annual mean $\mathrm{PM}_{2.5}$, with a model mean increase of $0.43 \mu \mathrm{g} / \mathrm{m}^{3}$ ( -0.25 to $\left.1.71 \mu \mathrm{g} / \mathrm{m}^{3}\right)$. Furthermore, at least five of seven models yield a $\mathrm{PM}_{2.5}$ increase in nine of ten world regions, with Africa the exception. These results are similar to those obtained by Silva et al. (2017), who focused on the ACCMIP models.

Consistent with the GHG-induced increase in $\mathrm{PM}_{2.5}$, five of seven models indicate an increase in premature mortality based on LC and CPD in eight of the ten world regions (Australia and Africa the lone exceptions). Furthermore, the majority of models yield an increase in global mean premature mortality. Although the model mean global average premature mortality increases in all future-population scenarios, the magnitude varies by a factor of $\sim 2$ depending on the SSP, ranging from 143,704 deaths/year in SSP4 to 265,112 deaths/year in SSP3. This range of future premature mortality covers the corresponding estimate of 215,000 deaths/year using future-population projections from the International Futures (IFs) integrated modeling system with four diseases (Silva et al. 2017).

We also note that this increase in $\mathrm{PM}_{2.5}$ and associated premature deaths likely represent an upper bound, since future projected decreases in aerosol emissions will counter the increase in $\mathrm{PM}_{2.5}$ due to climate change alone (Silva et al. 2016). Furthermore, our results are based on a business-as-usual warming scenario. To the extent that the increase in $\mathrm{PM}_{2.5}$ scales with warming, our results likely represent an upper bound.

Although our analysis implies GHG-induced climate change is likely to yield an increase in $\mathrm{PM}_{2.5}$ and associated premature mortality, several sources of uncertainties exist. Much of this uncertainty is related to model physics and the representation of aerosol processes (Regayre et al. 2018; Myhre et al. 2013). There is also uncertainty related to processes not included in our models, including vegetation (e.g., changes in biogenic emissions) and changes in the frequency and intensity of wildfire emissions. Previous studies indicate that climate change is expected to increase wildfires (Kasischke and Turetsky 2006; Wotton et al. 2017), resulting in more biomass burning $\mathrm{PM}_{2.5}$. This implies possible underestimation of the increase in $\mathrm{PM}_{2.5}$ and the associated premature mortality shown here.

Another source of uncertainty is that we assume our CRF, which is based on epidemiological studies in North America, applies globally. This is despite differences in health status, lifestyle, medical care, and make-up of $\mathrm{PM}_{2.5}$. Furthermore, our CRF is based on present-day conditions, but is assumed to be valid through this century. This assumption does not account for

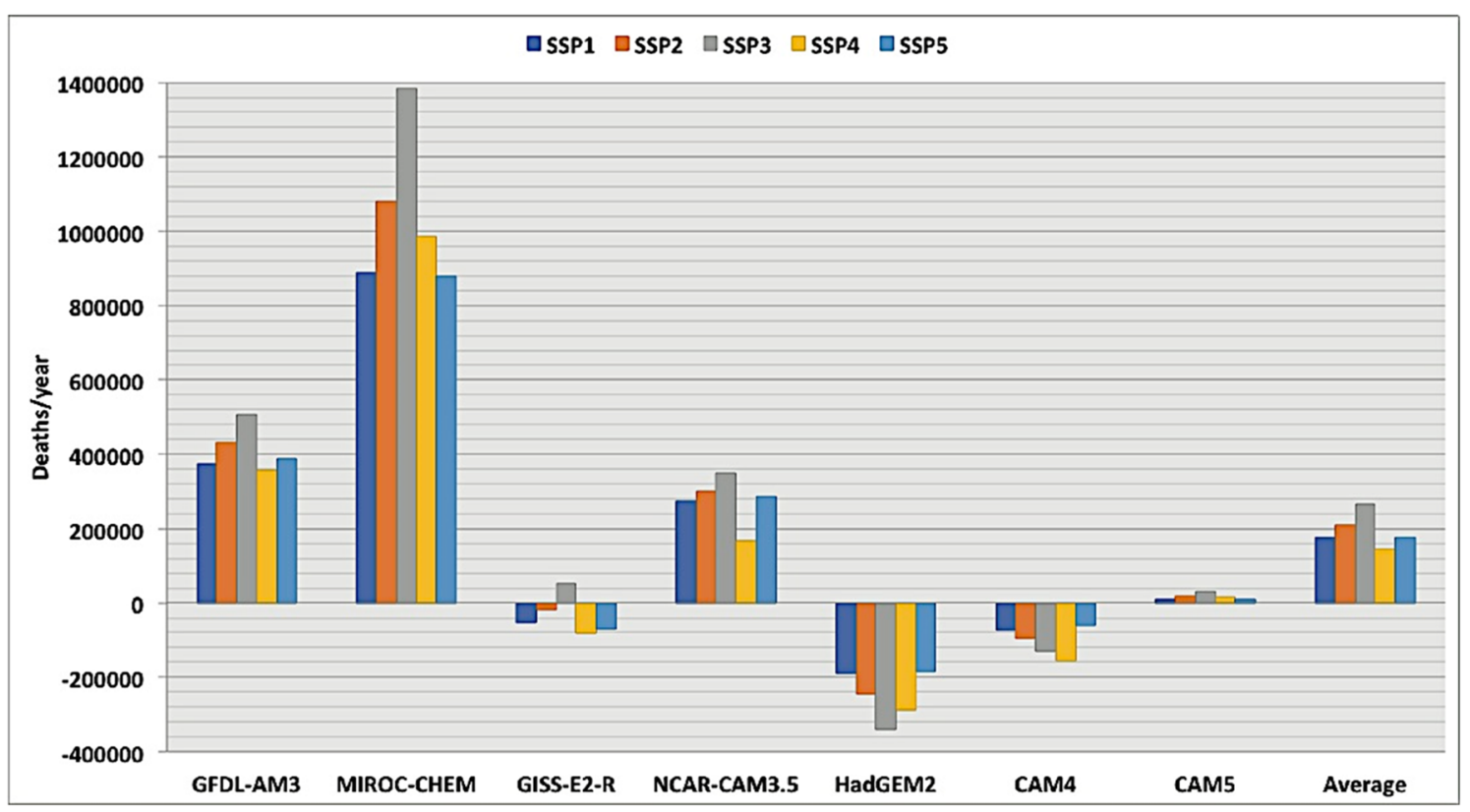

Fig. 4 Global premature mortality based on future projected population (SSPs) by seven models 
possible adaptation, including changes in susceptibility. Although these assumptions are necessary due to limited data, we caution that they may have significant impacts on our conclusions.

Uncertainty associated with future population is assessed from the five SSPs population scenarios (Supplementary information). Each future population is estimated by different assumptions related to education level, fertility, and migration (Riahi et al. 2017). We have also assumed (1) the ratio of population age 30 and above to total population is uniformly distributed within each country, and (2) the spatial distribution of future population is identical to the presentday spatial distribution within each country. However, world population forecasts indicate an increase in life expectancy and median age, implying a larger proportion of people age 30 and above in the future, relative to the present-day. Moreover, world population forecasts indicate an increase in the percentage of urban population, and this is also where the bulk of anthropogenic aerosol emissions occur. Both of these factors likely imply that we may underestimate the human health risks associated with future changes in $\mathrm{PM}_{2.5}$ in a warmer world.

Our results indicate that the model mean estimate of global premature deaths, averaged over five future population projections, is 194,448 deaths/year ( $-249,976$ to $1,043,850$ deaths/year). Thus, although future population projections contribute some uncertainty, differences in model physics lead to the large range of $\mathrm{PM}_{2.5}$-associated premature deaths. Moreover, this study indicates that future increases in $\mathrm{PM}_{2.5}$ due to GHG-induced warming are likely associated with human health risks, including premature mortality. Despite the limitations of our study, our results support the need for strict reductions in air pollution emissions, to avoid the possible adverse health effects of elevated $\mathrm{PM}_{2.5}$ concentration in a warmer world.

Acknowledgments We acknowledge the climate modeling groups participating in the Atmospheric Chemistry and Climate Model Intercomparison Project (ACCMIP) for producing and making available their model output.

Funding information This research was funded by NSF award AGS1455682 and by the Korea Meteorological Administration Research and Development Program under Grant KMI2018-01112.

Open Access This article is licensed under a Creative Commons Attribution 4.0 International License, which permits use, sharing, adaptation, distribution and reproduction in any medium or format, as long as you give appropriate credit to the original author(s) and the source, provide a link to the Creative Commons licence, and indicate if changes were made. The images or other third party material in this article are included in the article's Creative Commons licence, unless indicated otherwise in a credit line to the material. If material is not included in the article's Creative Commons licence and your intended use is not permitted by statutory regulation or exceeds the permitted use, you will need to obtain permission directly from the copyright holder. To view a copy of this licence, visit http://creativecommons.org/licenses/by/4.0/.

\section{References}

Allen RJ, Landuyt W, Rumbold ST (2016) An increase in aerosol burden and radiative effects in a warmer world. Nat Clim Chang 6:269-274

Allen RJ, Hassan T, Randles CA, Su H (2019) Enhanced land-sea warming contrast elevates aerosol pollution in a warmer world. Nat Clim Chang 9:300-305

Anenberg SC, Horowitz LW, Tong DQ, West JJ (2010) An estimate of the global burden of anthropogenic ozone and fine particulate matter on premature human mortality using atmospheric modeling. Environ Health Perspect 118:1189-1195

Bhaduri B, Bright E, Coleman P, Dobson J (2002) LandScan: locating people is what matters. Geoinfomatics 5:34-37

Burnett RT, Arden Pope C III, Majid E, Olives C, Lim SS, Mehta S, Shin $\mathrm{HH}$ et al (2014) An integrated risk function for estimating the Global Burden of Disease attributable to ambient fine particulate matter exposure. Environ Health Perspect 122:397-403

Collins WJ, Bellouin N, Doutriaux-Boucher M, Gedney N, Halloran P, Hinton $\mathrm{T}$ et al (2011) Development and evaluation of an Earthsystem model-HadGEM2. Geosci Model Dev 4:1051-1075

Fang Y, Mauzerall DL, Liu J, Fiore AM, Horowitz LW (2013) Impacts of 21 st century climate change on global air pollution-related premature mortality. Clim Chang 121:239-253

Health Effects Institute International Scientific Oversight Committee. 2004. Health effects of outdoor air pollution in developing countries of Asia: a literature review. Special Report 15. Boston:Health Effects Institute

Health Effects Institute (2010) Public Health and Air Pollution in Asia (PAPA): coordinated studies of short-term exposure to air pollution and daily mortality in four cities (HEI research report 154). Health Effects Institute, Boston

Hoek G, Brunekreef B, Goldbohm S, Fischer P, van den Brandt P (2002) Association between mortality and indicators of traffic-related air pollution in the Netherlands: a cohort study. Lancet 360:1203-1209

Jacob DJ, Winner DA (2009) Effect of climate change on air quality. Atmos Environ 43:51-63

Jerrett M, Burnett RT, Pope CA, Ito K, Thurston G, Krewski D, Shi YL, Calle E, Thun M (2009) Long-term ozone exposure and mortality, New Engl. J Med 360:1085-1095

Kasischke ES, Turetsky MR (2006) Recent changes in the fire regime across the north American boreal region - spatial and temporal patterns of burning across Canada and Alaska. Geophys Res Lett 33: L09703

Krewski D, Jerrett M, Burnett RT, Ma R, Hughes E, Shi Y et al (2009) Extended follow-up and spatial analysis of the American Cancer Society study linking particulate air pollution and mortality (HEI research report 140). Health Effects Institute, Boston

Lamarque J-F, Bond TC, Eyring V, Granier C, Heil A, Klimont Z et al (2010) Historical (1850-2000) gridded anthropogenic and biomass burning emissions of reactive gases and aerosols: methodology and application. Atmos Chem Phys 10:7017-7039

Lamarque JF, Shindell DT, Josse B, Young BJ, Cionni I, Eyring V et al (2013) The Atmospheric Chemistry and Climate Model Intercomparison Project (ACCMIP): overview and description of models, simulations and climate diagnostics. Geosci Model Dev 6: 179-206

Lelieveld J, Evans JS, Fnais M, Giannadaki D, Pozzer A (2015) The contribution of outdoor air pollution sources to premature mortality on a global scale. Nature. 525:367-371

Lepeule J, Laden F, Dockery D, Schwartz J (2012) Chronic exposure to fine particles and mortality: an extended follow-up of the Harvard Six Cities Study from 1974 to 2009. Environ Health Perspect 120(7):965-970 
Mickley LJ, Jacob DJ, Field BD, Rind D (2004) Effects of future climate change on regional air pollution episodes in the United States. Geophys Res Lett 31:L24103

Moss RH, Edmonds JA, Hibbard KA, Manning MR, Rose SK, van Vuuren DP et al (2010) The next generation of scenarios for climate change research and assessment. Nature 463:747-756

Myhre, G., D. Shindell, F.-M. Bréon, W. Collins, J. Fuglestvedt, J. Huang, et al., 2013: Anthropogenic and natural radiative forcing. In Climate change 2013: the physical science basis. Contribution of Working Group I to the fifth assessment report of the Intergovernmental Panel on Climate Change. T.F. Stocker, D. Qin, G.-K. Plattner, M. Tignor, S. K. Allen, J. Doschung, A. Nauels, Y. Xia, V. Bex, and P.M. Midgley, Eds. Cambridge University Press, 659-740

Nawahda A, Yamashita K, Ohara T, Kurokawa J, Yamaji K (2012) Evaluation of premature mortality caused by exposure to $\mathrm{PM}_{2.5}$ and ozone in East Asia: 2000, 2005, 2020. Water Air Soil Pollut 223:3445-3459

O’Neill BC, Kriegler E, Riahi K, Ebi KL, Hallegatte L, Carter TR et al (2014) A new scenario framework for climate change research: the concept of shared socioeconomic pathways. Clim Chang 122:387400

Post ES, Grambsch A, Weaver C, Morefield P, Huang J, Leung LY, Mahoney H (2012) Variation in estimated ozone-related health impacts of climate change due to modeling choices and assumptions. Environ Health Perspect 120:1559-1564

Regayre LA, Johnson JS, Yoshioka M, Pringle KJ, Sexton DMH, Booth BBB, Lee LA, Bellouin N, Carslaw KS (2018) Aerosol and physical atmosphere model parameters are both important sources of uncertainty in aerosol ERF. Atmos Chem Phys 18:9975-10006

Riahi K, van Vuuren DP, Kriegler E, Edmonds J, O’Neill B, Fujimori S et al (2017) Shared socioeconomic pathways: an overview. Glob Environ Chang 42:153-168

Samir KC, Wolfgang L (2017) The human core of the shared socioeconomic pathways: population scenarios by age, sex and level of education for all countries to 2100. Glob Environ Chang 42:181-192
Shen L, Mickley LJ, Murray LT (2016) Influence of 2000-2050 climate change on particulate matter in the United States: results from a new statistical model. Atmos Chem Phys 17:4355-4367

Silva RA, West JJ, Zhang Y, Anenberg SC, Lamarque JF, Shindell DT et al (2013) Global premature mortality due to anthropogenic outdoor air pollution and the contribution of past climate change. Environ Res Lett 8:034005

Silva RA, West JJ, Lamarque JF, Shindell DT, Collins WJ, Dalsoren S, Faluvegi G, Folberth G, Horowitz LW, Nagashima T, Naik V, Rumbold ST, Sudo K, Takemura T, Bergmann D, Cameron-Smith P, Cionni I, Doherty RM, Eyring V, Josse B, MacKenzie I, Plummer D, Righi M, Stevenson DS, Strode S, Szopa S, Zeng G (2016) The effect of future ambient air pollution on human premature mortality to 2100 using output from the ACCMIP model ensemble. Atmos Chem Phys 16:9847-9862

Silva RA, West JJ, Lamarque J-F, Shindell DT, Collins WJ, Faluvegi G, Folberth GA, Horowitz LW, Nagashima T, Naik V, Rumbold ST, Sudo K, Takemura T, Bergmann D, Cameron-Smith P, Doherty RM, Josse B, MacKenzie I, Stevenson DS, Zeng G (2017) Future global mortality from changes in air pollution attributable to climate change. Nat Clim Chang 7:647-651

United Nations, Department of Economic and Social Affairs, Population Division 2015 World Population Prospects: The 2015 Revision custom data acquired via website

Westervelt DM, Horowitz LW, Naik V, Tai APK, Fiore AM, Mauzerall DL (2016) Quantifying PM $_{2.5}$-meteorology sensitivities in a global climate model. Atmos Environ 142:43-56

Wotton, B. M., Flannigan, M. D. and Marshall, G. A, 2017: Potential climate change impacts on fire intensity and key wildfire suppression thresholds in Canada. Environ Res Lett 12. 095003

Publisher's note Springer Nature remains neutral with regard to jurisdictional claims in published maps and institutional affiliations. 